\title{
TORTURA E CONTAMINAÇÃO EM ADAPTAÇÃO DO FUNCIONÁRIO RUAM
}

(1975)

\section{TORTURE AND CONTAMINATION IN ADAPTAÇÃO DO FUNCIONÁRIO RUAM}

Recebido: 13/01/2021

Aprovado: $17 / 05 / 2021$

Publicado: 30/07/2021

DOI: $10.18817 /$ rlj.v5i01.2497

Eduardo Prado Cardoso ${ }^{1}$ https://orcid.org/0000-0002-8050-334X

\begin{abstract}
Resumo: O artigo propõe uma leitura da novela Adaptação do funcionário Ruam, publicada em 1975 por Mauro Chaves, a partir de dois principais eixos: um que inscreve a tortura em ordem semiótica como teorizado por Isabel Capeloa Gil (2016), e outro que analisa a contaminação proposta pela obra na chave de Foucault (1978; 1999), a partir de suas relações com a loucura e com a disciplina. Através de exemplos de cenas nas quais projeções holográficas, desejos masculinos e castigos físicos ou psicológicos revelam o diálogo da ficção distópica com o contexto brasileiro ditatorial, busca-se uma crítica da literatura como espaço projetivo e de epistemologias alternativas.
\end{abstract}

Palavras-chave: Ficção científica brasileira. Anos 70. Ditadura militar brasileira. Literatura distópica. Representações da violência.

Abstract: This paper offers a reading of the novel Adaptação do funcionário Ruam, published in 1975 by Mauro Chaves, taking into consideration two main strands: one that inscribes torture in a semiotic order - as theorized by Isabel Capeloa Gil (2016), and another which analyses the concept of contamination found in the novel through Foucault's writings $(1978 ; 1999)$, highlighting the ideas of madness and discipline. Illustrating the essay with scenes in which holographic projections, masculine desire and physical or psychological punishment reveal dialogues between dystopian fiction and the Brazilian dictatorial context, we expect to shed light on how literature can work as a projective space that forges alternative epistemologies.

Keywords: Brazilian Science-fiction. 1970's. Military dictatorship in Brazil. Dystopian literature. Representations of violence.

\section{A cartilha distópica em Adaptação do funcionário Ruam}

Publicada em 1975, a novela Adaptação do funcionário Ruam permanece obscura para a crítica acadêmica, o que diz mais a respeito da falta de interesse pelo gênero literário em que ela se inscreve do que pelos temas e opções estilísticas da obra de Mauro Chaves. A julgar pela pertinência de alguns de seus tópicos de preferência - como mudança climática, autoritarismo e pós-humanismo - bem como

\footnotetext{
${ }^{1}$ Doutorando em Estudos de Cultura na Universidade Católica Portuguesa e bolsista da Fundação para a Ciência e a Tecnologia. Graduado em Audiovisual pela ECA-USP, pesquisa representações de violência, modernidade, culturas de massa e populares. E-mail: oeduardoprado@gmail.com
} 
o período em que foi escrito, é surpreendente que sua fortuna crítica se restrinja a posicioná-lo no campo da ficção científica brasileira. De fato, a obra é exemplar na enunciação da distopia clássica ${ }^{2}$, mas tentarei demonstrar aspectos formais e temáticos que a singularizam a partir de dois eixos: um ligado à tortura (projetada, sonhada, desejada e temida) e o outro que alicerça a história a partir da contaminação (tocando esferas de resistência, racionalidade e encarceramento). O primeiro eixo será aqui sistematizado a partir da conceitualização de tortura literária proposta por Isabel Capeloa Gil (2016), enquanto o segundo explorará pontos de contato entre os Contaminados de Adaptação do funcionário Ruam e a violência, o medo e a institucionalização da loucura descritos por Michel Foucault (1978; 1999). Pretendo, assim, demonstrar como a novela de Chaves, ao se colocar como projeção catastrófica do Brasil em diversos parâmetros, acaba por questionar tanto o regime opressivo de sua época, quanto os leitores, cuja base de conhecimento e descoberta subjetiva são postos em xeque.

Partindo-se das características definidoras levantadas por Graham J. Murphy sobre três obras seminais para a distopia como subgênero da ficção científica - Nós (1924), de Yevgeny Zamyatin, Admirável mundo novo (1932), de Aldous Huxley e 1984 (1948), de George Orwell, observa-se que a Adaptação do funcionário Ruam aplicou-se a cartilha da narrativa distópica, no que tange a formas, tensões e resoluções. Nas obras citadas, diz Murphy,

(...) as guerras facilitam a ascensão da distopia; as recentes descobertas dos protagonistas passam por um teste; o feminino, o amor e o desejo carnal motivam a resistência; linguagem é uma ferramenta tanto de opressão quanto de liberação; rituais quase religiosos são proeminentes; e o utopismo é levado ao limite das trevas ${ }^{3}$ (MURPHY, 2009, p. 474, tradução nossa).

Chaves constrói seu Brasil fictício precisamente a partir de um governo autoritário (a Potestade), cuja história recente conta sobre disputas sangrentas com os vizinhos latino-americanos pela Amazônia; em Adaptação do funcionário Ruam, o protagonista do título é um oficial cuja epifania sobre a manipulação do Grande

\footnotetext{
${ }^{2} E$ só a inscrição nesse subgênero já suscitaria a crítica de múltiplos envolvimentos mútuos entre sociedade e literatura como nenhum outro, como destaca M. Keith Booker (BOOKER, 1994, p. 175).

3 No original: "(...) wars facilitate dystopia's ascendancy; protagonists endure some trial of their newfound beliefs; women, love, and carnal desire motivate resistance; language is both an oppressive and liberating tool; quasi-religious rituals are prominent; and utopianism is pushed to the very brink of darkness."
} 
Sistema se dá através do contato com seu amor de juventude, Miraia; a descrição da violência impelida aos opositores, chamados de Contaminados, mistura o desejo de Ruam pela volta ao corpo protetor e materno com a subjetividade masculina autoritária de uso descartável do feminino; a língua usada pelo autor, ao lançar mão de neologismos que indicam certo futuro possível para as palavras no Brasil (São Paulo é Sao, Amazônia é Amazonlanda, delatochoques e jusconfessadores são os instrumentos de tortura), a obra indica que a linguagem, por operar mixagem na superfície, deverá guiar descobertas por si própria; tanto as cenas de participação de Ruam em demonstrações de força e virilidade com as tropas (incluindo as reuniões em saunas), como as práticas esportivas e festivas (o granesporte fotebol é rotina obrigatória, e o Carneval, distração imposta), inserem-se no campo dos rituais; no livro, a ideia do novo homem, o purimarrono, é traduzida aos habitantes brazileinos através de microcomputadores e tecnologias avançadas, e o maquinário laudatório do próprio regime é tão confiante que criou até mesmo um ilusório espaço para o dissenso, o controlado Departamento de Contestação.

No caminho pavimentado pela novilíngua orwelliana, Adaptação do funcionário Ruam encontra as bifurcações e os becos sem saída que tanto atormentaram os pensadores do século XX. Como pontua Gonçalo M. Tavares (2021), as obras 1984, Na colônia penal (Franz Kafka, 1919) e Vigiar e punir (Michel Foucault, 1975) dialogam sobre as relações Estado-lei-corpo de maneira tão seminal justamente por registrarem na linguagem a sombra autoritária e ubíqua percebida em suas épocas. Ciente de que não somente a distopia, mas os imaginários legados por tais autores forneciam dispositivos epistemológicos para enfrentar o racionalismo arbitrário de seu tempo, Mauro Chaves criou uma alternativa futurista na qual as aflições da tortura e da contaminação formam bases para a opressão ou para a libertação.

\section{Tortura como projeção}

A ordem dos paradigmas literários instaurados por Kafka e Foucault é tal que Isabel Capeloa Gil também os elege como fontes para se pensar a representação da tortura na literatura. Em Fragile Matters: Literature and the Scene of Torture, a autora os relaciona diretamente: 
Em nota menos alegórica, a dimensão jurídico-epistemológica da tortura testemunhou várias reformas (...). Como a punição foi "civilizada" nas ondas reformistas de fins do século XVIII, a tortura foi banida de tratados jurídicos, como Foucault mostra de maneira perspicaz no seminal Vigiar e punir. (...) O novo enquadramento civilizado da tortura passou por uma renomeação, reordenando o que antes era um espetáculo decisório em instrumento dissimulado da micropolítica, eventualmente recorrendo às retóricas "técnicas de interrogatório aprimoradas". (...) O sistema de tortura se converte em aventura semiológica, na qual o ato da violência é empregado como elemento de uma floresta incorporada de sinais que a vítima é convidada a ler e discernir. Tal tortura semiótica se sobressai em Na colônia penal, de $K_{\text {Kafka }}^{4}$ (GIL, 2016, p. 132, tradução nossa).

Ainda que Gil faça a ressalva de que uma leitura estritamente foucauldiana sobre os regimes de sentido propostos por Kafka não dê conta dos códigos linguísticos contidos na grotesca prisão racionalista da ficção, é no cruzamento do processo civilizacional do castigo físico com as formas de se encontrar a verdade que a literatura encontrou forte expressividade, por ser a própria escrita um meta-processo, por vezes enunciando-se como resistência à tortura apresentada. Nesse sentido, a ficção científica fornece, como prova Chaves, terreno fértil para projeções de várias grandezas. Proponho uma leitura das cenas de tortura em Adaptação do funcionário Ruam tomando como base o conceito de Gil sobre a citada tortura semiótica, segundo a qual boa parte do conflito existencial emana da dificuldade em se decifrar os códigos arbitrários da diegese. Para situar a principal cena a descrever tortura física e psicológica da novela, cabe uma primeira análise do procedimento metafórico projetivo eleito por Chaves $^{5}$, o qual fica subentendido em outros relatos - são assim nomeados os capítulos, por aludirem aos registros de uma certa Unidade de Computação, moldura típica do sci-fi.

Ao descrever o Departamento de Contestação como parte integrante do Palácio de Cortiça, construção física e politicamente flexível, aparentemente a

\footnotetext{
${ }^{4}$ No original: "On a less allegorical note, the juridico-epistemological dimension of torture witnessed several refurbishments (...). As punishment was "civilized" in the reform waves of the late eighteenth century, torture was banned from juridical treaties, as Foucault insightfully shows in the seminal Surveiller et punir. (...) The new civilized framing of torture went through renaming, reinstructing what was formerly a spectacle of decision into a secretive instrument of micropolitics, eventually running to the rhetorical "enhanced interrogation techniques." (...) The system of torture becomes a semiological adventure, in which the act of violence is emplaced as an element of an embodied forest of signs the victim is invited to read and discern. This semiotic torture stands out in Kafka's "In the Penal Colony," (...).

${ }^{5}$ Procedimento esse que é intrínseco à distopia, que, como escreve Fátima Vieira: "prevê que as coisas terão consequências trágicas; é, portanto, essencialmente pessimista na sua apresentação de imagens projetivas." (VIEIRA, 2010, p. 17, tradução nossa)
} 
acomodar a divergência, o relato 11 coloca o agora convertido Ruam como funcionário que projeta cenas de barbárie da guerra ao mesmo tempo em que as festividades da Potestade ocupam mentes e corpos:

\begin{abstract}
Ali agora preparava a projeção de cenas holografadas. Terríveis visos tridimensos das antigas batalhas de ocupação. Bombardeios de napalmdum, visos sanguinados de pequenitos morrentes. Destruição de moradas, soterramentos, gestos esgares dolorríveis. Mas tudo mixado a cenas e figuras bufonadas, fantasiadas ridentes, em megadores, que era tempo de Carneval. E comemoração (CHAVES, 1975, p. 44).
\end{abstract}

A estratégia de levar a verdade aos que não fazem parte da resistência docemente dominada se dá por tecnologia visual, através da qual a materialidade violenta tenta criar lastro histórico, porém a recepção é invariavelmente fria. Colocando em causa maquinários epistemológicos (como a própria novela), os relatos remetem à problemática do uso da linguagem técnica não somente na manipulação de discursos, mas também do potencial atrativo ao se narrar a história. Neste trecho do relato 14, a condição de Contaminado de Ruam se manifesta na falta de recursos para se disseminar o conhecimento sobre o próprio sistema:

Reassumindo agora o seu grupo vilativo Ruam topou com o enorme trabalho.
Em vista dos outros, seu estande era o mais pobre, pior equipado.
Desapoiado mais que todos, prejudicado. Sua mostra só consistia na
projeção de velhas fitas holografadas, com o tema da ocupação dos
Protetorados. Maledades cometidas pelo Grande Sistema, cenas de tortura,
massacres de outros povos. Dispunha de um velho obsoleto projetor laser.
De mais de vinte anos. Suas imagens tridimensas distavam muito das novas
técnicas de holografia, usadas perfeitas nas campanhas publicitárias do
Grande Sistema. Que misturava, como podia, funcionários reais e irreais, os
holografados. Transformados em enormes exércitos, maravilhosos, de gente
inexistente. Técnica já usada em antigas guerras (CHAVES, 1975, p. 60).

Como se percebe, as pistas sobre a tortura (explicitamente citada) e a violência empregadas pelo Grande Sistema residem na própria ideia de que os Contaminados, ao pretensamente competirem com discursos de técnica mais avançada, precisam projetar a verdade de alguma maneira diante dos olhos dos outros, para então que se faça a verdade. Pretensamente, pois, como veremos adiante, está problematizada mais que a legitimidade das imagens, a própria ontologia narrativa, e portanto, dos relatos diegéticos mesmos. Em outro trecho iluminador, Ruam e os Contaminados notam a clara distância entre o discurso audiovisual holográfico e os outros brazileinos: 
Entrou um primeiro visitante. Aproximou-se do local do estande onde se movimentavam as figuras hologramas. Fazendo a guerra, que fora uma dos Protetorados. A do Colombino, das mais resistentes, sanguenadas. Pequenitos morrentes esmagados pelas botas dos funcionários brazileinos. De armitropa, gloriosos. Mulheres colombinas violadas, bundencoxadas nuas, culadas e chupadas ante o viso de seus pequenitos. Lutadores colombinos despejados por afiadas navalhas que cimavam as baionetas. Ou injetados de líquido dumdum, explodidos depois, com suas partes espalhadas sobre as árvores, pelos pântanos, pelos tetos das moradas e seus quintais. Viu os letreiros que cintilavam frases de ataque ao Grande Sistema e à Potestade. Tais como: "Somos os opressores dos povos irmanas". "O Grande Sistema é o cemitério Podrenojo da nossa liberdade." "Nossa riqueza é maledita a todos os seres do mundo." "A Potestade nos levará ao desastre final." "O Grande Caminho é a rode dos desonestos." Meio-estonteado o funcionário visitante aí resmungou a princípio baixo, quase em sussurro: - Isso não é verdade. Abanando a cabeça: - Não acredito. Abanando mais forte, altibradando de repente: - Não é verdade! Não acredito! Voltando-se tonagressivo para os equipados: - Isso tudo vocês montaram para nos impressionar! Vocês são uns miseráveis Contaminados! Traidores!!! E aí escramou chispado e gritando até fora do estande: - É mentira!!!. .. É mentira!!! Não acredito!!!... Sumindo entre o magote que já tomava todos os corredores do Palácio de Cortiça (CHAVES, 1975, p. 61).

Quando nem mesmo acompanhadas de frases de luta contra o governo autoritário as imagens conseguem persuadir o visitante do Departamento de Contestação, o que está em discussão é a inversão característica da novilíngua de 1984, quando paradoxos como "liberdade é escravidão" (ORWELL, 2009, p. 10) trazem à tona o falso racionalismo praticado pelo governo - uma vez que ele não é flexível como se vende, e manipula mentalmente seus cidadãos para desacreditarem a resistência. Os horrores detalhados pelos hologramas revelam uma questão de gênero evidente (a ser discutida ainda neste tópico sobre a tortura), assim como a escolha do autor em permear a trajetória de Ruam com o binômio verdade-mentira, caro às técnicas de interrogatório ditatoriais e que pauta, no ambiente distópico, o desafio inerente à leitura. O funcionário visitante, ao ser confrontado com a representação da tortura enquanto denúncia, logo se volta contra o sistema panfletário, enquanto o agente perpetrador das atrocidades permanece invisível - de certa maneira, Adaptação do funcionário Ruam revela o próprio procedimento discursivo idealizado para alcançar, em seu interior, a mente de Ruam, e no exterior, como um espelho, nós, leitores. No próprio contexto brasileiro de 1975, o objetivo parece crítico às modalidades de discurso de chegada da verdade, além da óbvia denúncia à violência ditatorial. 
É a sequência de tortura de Miraia, no entanto, a mais singular da novela. Em uma primeira camada, ela mantém a temática projetiva (uma vez que produzida pelos aparelhos de jusconfessadores ${ }^{6}$, injetores de pesadelos com tecnologia avançada); em outra, o relato sinaliza uma construção da tortura como desejo, sonho e projeto:

Que no da última noite ela estava no Granorquidário Paraizo. Passerenava na estufa das orquídeas gigantes cujo perfume sempre amara. De repente começou a ouvir um zumbido lindo que foi crescendo enquanto o floroma aumentava. Mais intenso, ainda mais, até um ponto em que deixava de ser naridoce e o zumbido de canto ouvidoce também virava um langorido insuportável. Cada vez mais. Um cheiro podrenojo de sentina que aumentava fetilento vomitoso. Enquanto as belas arcorquídeas pretavam e empeludeciam com cabelos enormes, de repente. Gritou então desesperada, tentou com a mão tapar o cheiro, ouvidos e olhos. Mas os cabelos gigantes eram laços que amarravam seus braços. Depois começavam a penetrar as corpofendas, enfiando por cheiro boca buceta e análias até às vísceras que amarravam e apertavam em megadores lancinantes. Ao acordar ainda sentia os efeitos doídos em todas as partes corpunidas. E era o castigo já reduzido em setenta porcento. Desde o último aprocho com o injetor, tinha quarenta dias. Mas a punição dos Contaminados nunca chegava a níveis realmente insuportáveis, de perecer. Porque o Grande Sistema não queria a adesão total. O Departamento de Contestação tinha de ser preservado, segundo os desígnios da Potestade. A espera dos Contaminados era a de que os limites se alargassem até o descontrole de caosoar e fagotar o Grande Sistema e a Potestade. Isso que Miraia também esperava. Sem importar de essa espera ser ou não já programada (CHAVES, 1975, pp. 17-18).

Ao invés de mero holograma, a representação de tortura adquire um caráter sinestésico, em que a dor se espraia pelos sentidos e confunde sonho com realidade. Mas em que medida o pesadelo violento de Miraia indica sua qualidade semiótica, como sugerimos? Reside, no enredo da novela, uma importante evolução: o fato de Miraia gostar de passear pelo orquidário, e ter a botânica como atividade preferida reflete uma projeção do próprio funcionário Ruam. Era nesse cenário que os dois tinham encontros amorosos e sexuais, rememorados pelo protagonista como portadores de "um perfume doce, tão doce, de sonho" (CHAVES, 1975, p. 37). Na comunhão carnal de Ruam e Miraia do relato 18, o tema da projeção reaparece:

Fizeram, repetiram e mais. $\mathrm{O}$ amor querido e negado, interrompido há tanto tempo. Ali juntos agora como deviam, sempre. Que eram os projetos cruzados e entrecruzados deles dois, Ruam Miraia, seratráteis. Desde

\footnotetext{
${ }^{6}$ A ideia de ficcionalizar aparatos de tortura no contexto autoritário em que se encontrava o Brasil sugere que a tal "leitura nas entrelinhas", de que falam Heloísa Buarque de Hollanda e Marcos Augusto Gonçalves e que "fica na ponta da língua e pode ser feita de formas mais ou menos complexas. Pode ir da alusividade esquemática de Fazenda Modelo de Chico Buarque à releitura política do trabalho da ambiguidade em José J. Veiga, ou à valorização oportuna dos traços realistas da violência em Rubem Fonseca." (FREITAS FILHO; HOLLANDA; GONÇALVES, 1981, p. 17), aqui é pouco ou nada sutil.
} 
sempre. Só que ali agora feito, realizado pleno, como sem antes (CHAVES, 1975, p. 78).

Desta feita, a acepção conjuga, além da projeção pertinente a uma representação técnica como a holografia, tópicos como destino e controle. Como em outras distopias, o amor erótico, por romper concepções puramente utilitárias, é tomado como a outra face da arbitrariedade da Potestade. No entanto, como é de se esperar, também a projeção do desejo já foi cooptada pelo Grande Sistema, sendo a própria Miraia um mecanismo projetivo que ludibria Ruam para testá-lo e fazê-lo voltar do lado dos Contaminados. No relato final da novela, após o funcionário do título passar por diferentes realidades e duvidar do Sistema, um funcionário externo narra a provável futura execução de Ruam (por muito duvidar) pelas mãos daquela que ele acredita ser seu verdadeiro amor, detentora de uma história real, singular, destinada a ele.

Tal choque resolutivo da história, através do qual os leitores reavaliam toda a narrativa, oferece, então, ares de contestação para a projeção de tortura aqui citada. $\mathrm{O}$ corpo de Miraia, estuprado no seu pesadelo, pode ter pertencido à personagem em um passado em que não havia sido manipulada pela Potestade, ou, se ela nunca exigiu com tal subjetividade e foi inteiramente construída apenas para dar cabo de Ruam, o discurso da tortura recai sobre a própria imaginação do corpo feminino sendo torturado - em outras palavras, ao suspender os patamares epistemológicos que estavam ao alcance dos leitores até então, Chaves atualiza a cena de tortura como uma perversa zona em que é preciso se caçar os sinais de verdade e mentira, da mesma maneira que regimes de exceção tentam instaurar realidades pseudoracionais em busca de delações e confissões que eles próprios criaram. O mecanismo revela, portanto, a um passo a projeção do funcionário Ruam através do corpo de Miraia, e também do autor Mauro Chaves, cuja noção de representação de tortura do corpo feminino (como visto na cena de guerra) seria das mais obscenas e cruéis, pois atrelada ao corpo desejado e vulnerável da mulher. A temática sexual, aliás, é das mais relevantes para Adaptação do funcionário Ruam. Quando, ao final, o protagonista adentra uma fenda temporal e se vê em uma São Paulo contemporânea à época do autor, os paulistanos tomam Ruam por louco por falar em outra língua e sobre a tal Potestade, e em um sanatório ele é estuprado por dois funcionários. Logo se vê que a tortura sexual, como punição ou prazer de outrem, é constitutiva do 
universo de Chaves, mas o que destaco como positiva é a exposição do sistema como operador de tais desejos violentos. Fosse Miraia apenas personagem-objeto do desejo de Ruam, a relação entre leitores e novela poderia se restringir à economia indiciária da diegese (torcer para que o amor escape à arbitrariedade) - no entanto, como a própria diegese encapsula e evidencia o discurso da projeção, e, por conseguinte, da tortura, tem-se uma crítica mais apurada dos mecanismos representativos em tempos de exceção. Que o Grande Sistema iria a fundo para entender um certo desejo masculino para recriar o estupro de Miraia, em detalhes fantásticos e que ao mesmo tempo enternecem e excitam o funcionário Ruam, só vem demonstrar que a prática representativa da tortura é calcada em traços culturais bastante palpáveis de seu tempo. O projeto epistemológico desta distopia parece, assim, querer vingar um mundo de possibilidades redentoras (com suas expressões sobre o amor e a natureza), ao mesmo tempo em que elas são postas à prova, projeções manipuladas que são. No fundo, o autor toma para si a função verdadeiramente reveladora, uma vez que o próprio processo literário é feito visível, em toda a sua potência. A cena de tortura, nesse pressuposto, atua sim em cruel universo de aventura, como colocou Gil, mas abre aí um espaço para que tais buscas de significado contestem as realidades que a novela metaforiza.

\section{Os Contaminados: loucos e úteis}

Ora, se a contestação no universo de Ruam, funcionário de um departamento de resistência dentro do sistema, é, então, sobreposta pela discussão do dispositivo epistemológico da própria novela, é necessário se discutir o outro grande eixo que a constitui, a questionar sistemas de disciplina e sanidade. Não somente a dissidência é claramente nomeada no futuro de Chaves (os Contaminados), como é sujeita a práticas de tortura (como vimos na sequência do estupro e pesadelo de Miraia) e transplante compulsório de órgãos para os funcionários fieis à Potestade. Assim, o chamado "sangue podrenojo" (CHAVES, 1975, p. 33) dos Contaminados é temido mas de alguma forma incorporado na sociedade, tal qual o Departamento de Contestação é parte constitutiva do governo. Evocando uma mistura de técnicas de mordaça com aspectos do sistema colonial brasileiro, a novela mostra Ruam, como contaminado, passar de uma instituição militar para uma instituição psiquiátrica (como 
sabemos ao final, como um teste de sua fidelidade) em uma São Paulo do passado. O recurso narrativo, embora à primeira vista um simples artifício causador de surpresa para os leitores, evoca o próprio conceito de contaminação como base para se pensar outras instâncias que esta distopia problematiza, a saber: a loucura e a disciplina.

Descritos como "corpunidos, castigados" (CHAVES, 1975, p. 45), os Contaminados figuram, através do asco da sociedade por seus corpos e suas ideias dissidentes, um fenômeno histórico que Michel Foucault tão bem descreveu em História da loucura na Idade Clássica (1978) como uma longa e complexa construção social de afastamento e clausura tanto de pessoas com problemas mentais quanto dos apontados como marginais. Mais que isso, as etapas de produção de sentido sobre a loucura necessariamente passaram por mitologias e medos recuperados, com fortes reflexos no espectro político. Sobre desdobramentos do século XVIII na Europa, escreve o autor, a figura dos loucos habitou imaginários afinados ao seu tempo. Ainda que o lluminismo relegasse, cinicamente, pessoas que fugissem à norma aos sanatórios ou mesmo às ruas, considerando-os meros espelhos distorcidos do progresso, isso não evitou que um enorme medo abatesse a sociedade mesmo com o grande confinamento dos diferentes:

Bruscamente, em alguns anos no meio do século XVIII, surge um medo.
Medo que se formula em termos médicos mas que é animado, no fundo, por
todo um mito moral. Assusta-se com um mal muito misterioso que se
espalhava, diz-se, a partir das casas de internamento e logo ameaçaria as
cidades. Fala-se em febre de prisão, lembra-se a carroça dos condenados,
esses homens acorrentados que atravessam as cidades deixando atrás de si
uma esteira do mal. Atribui-se ao escorbuto contágios imaginários, prevê-se
que o ar viciado pelo mal corromperá os bairros habitados. E novamente se
impõe a grande imagem do horror medieval, fazendo surgir, nas metáforas
do assombro, um segundo pânico. (...) Impera então uma espécie de imagem
indiferenciada da "podridão", que diz respeito tanto à corrupção dos costumes
quanto à decomposição da carne, e pela qual irão pautar-se a repugnância e
a piedade sentidas em relação aos internos (FOUCAULT, 1978, p. 389).

Esse conceito de podridão enquanto poderoso sentimento e designação do desconhecido habita a novela de Chaves não apenas por uma coincidência de palavras. É exatamente a repugnância e a piedade pelos Contaminados que estrutura a sociedade do futuro. $O$ medo de pertencer aos castigados certamente explica a descrença nas ideias propagadas pelo Departamento de Contestação, como visto antes, quando o visitante tenta ignorar a realidade diante dos seus olhos - no entanto, há também uma certa condescendência típica do autoritarismo, cuja parcela dita 
neutra da sociedade julga que a resistência seja uma escolha inútil, propagada por um grupo de loucos e nada mais. A própria concepção de uma sociedade flexível, a compreender o dissenso, taxa os Contaminados como a minoria útil. Assim, denominá-los com a carga necessária de exclusão é fundamental para garantir-lhes um papel controlado no Grande Sistema, e que nunca realmente se converta em real ameaça à Potestade. Quando Ruam acredita ter caído o governo autoritário por este ter aberto uma brecha demasiadamente larga, trata-se de mera projeção interna para testá-lo, através de maquinações de Miraia. É num contexto de total manipulação, portanto, que o próprio conceito dos Contaminados na sociedade ganha vida.

O paradigma da flexibilidade útil ao sistema, aliás, liga-se ao que Michel Foucault caracterizou como uma das técnicas da disciplina:

Mas o princípio de "clausura" não é constante, nem indispensável, nem suficiente nos aparelhos disciplinares. Estes trabalham o espaço de maneira muito mais flexível e mais fina. E em primeiro lugar segundo o princípio da localização imediata ou do quadriculamento. Cada indivíduo no seu lugar; e em cada lugar, um indivíduo (FOUCAULT, 1999, p. 169).

Aqui Foucault se refere, especificamente, aos meios pelos quais o sistema prisional estabelece noções de força e controle - mas exatamente por fazê-lo dissecando estruturas comuns aos autoritarismos históricos ou ficcionais, permito-me iluminar como é desnecessária a prisão física na Sao de Ruam quando os aparelhos disciplinares estenderam-se a diversas práticas sociais. Sobre o fotebol, desporto compulsório, o relato 7 diz:

Todos os dias às dez da manhã e às cinco da tarde em ponto, toda a população era obrigada a praticar o granesporte brazileino. No lugar em que estivesse. Por isso que em todas as praças, ajuntamentos, granavenidas, estações, planos de underground, produtoras e centros comerceiros, havia uma área plastigramada para o exercício do fotebol. A prática bidiária durava quinze minutos. Por decreto graciado pela Potestade havia dezenas de anos. Todos, homens e mulheres dos oito aos noventa e oito anos eram obrigados (CHAVES, 1975, pp. 27-28).

Quando a Potestade rui, em ilusão proporcionada a Ruam, a descrição das práticas disciplinadoras abandonadas não poderia ser mais clara:

Eram quase cinco da tarde. Mas sabiam que não seriam interrompidos pelos apitores dos bolfderes. O fotebol das cinco fora abolido. Tanto o das dez. Por decreto da Junta Dos Gransecretários. Os plastigramados por que passavam jaziam abandonados. Ou aproveitados por alguns grupos de pequenitos. Não organizados, juerando. Também displicentes. Como parecia tudo naquela 
nova ordem, desde a renúncia da Potestade. Liberdade é displicência de todos (CHAVES, 1975, p. 69).

De um lado, destarte, vive-se a disciplina dos corpos: ainda que não habitem a clausura dos sanatórios ou das penitenciárias, os Contaminados precisam servir ao Grande Sistema sob pena de castigos e doações de órgãos. Do outro, o conceito que os caracteriza, a contaminação a separá-los dos adeptos da Potestade. A divisão disciplinadora, assim, parte dos corpos mas se pauta sobretudo no perigo representado pelas ideias divergentes dos antifascistas. Em um nível assustadoramente contemporâneo para o século XXI, em que as ilusões vendidas por governos autoritários sequer se travestem de bem-intencionadas, e exibem os horrores da guerra com a certeza de que a lavagem cerebral dos habitantes de Sao os interpretará como mentiras, a distopia de Mauro Chaves coloca, à sua maneira, os perigos de sistemas falsamente democráticos ${ }^{7}$. Quando a divergência recebe selos derrogatórios e passa a ocupar um espaço já programado, é porque a própria ideia de oposição já foi convertida em signos de insanidade ou criminalidade.

\section{Sobre epistemologias alternativas}

A tortura infligida ao corpo de Miraia, ciente de que ela não deve morrer, e sim sofrer continuamente, demonstra que as técnicas disciplinadoras flexíveis da Potestade escondem os verdadeiros sinais de sua maquinação maior ${ }^{8}$. Na última cena de Ruam, ele acompanha Miraia à entrada de um prédio. Percebe que a rigidez da sociedade ressurgiu, e os arbustos que antes haviam crescido desordenamente já não existem mais:

Ruam teve a sensação misturada de medo e tristeza. Duvidava de Miraia. Ela continuou, falando rápido. - Você não quer entender o nosso mapa? ... Pois lá dentro você vai ver... O nosso mapa está lá projetado, bem grande, por todas as paredes, pelo piso e pelo teto... Dessa vez você vai entender tudo, sem mais dúvidas. Ruam voltou-se para ver de novo os arbustos decepados. Estremeceu (CHAVES, 1975, p. 114).

\footnotetext{
${ }^{7}$ Relaciono, ainda, a falsa flexibilidade criada por Chaves como símbolo típico da narrativa distópica do período, uma vez que, como frisou Andrew Hammond, tanto o espectro do totalitarismo como a noção de "mundo-livre" compuseram discursos políticos durante a Guerra Fria (2020, p. 64).

${ }^{8}$ A qual, em última análise, parece coincidir com a fala de um dos líderes de 1984: "Poder não é um meio, mas um fim. Não se estabelece uma ditadura para proteger uma revolução. Faz-se a revolução para instalar a ditadura. $\mathrm{O}$ objetivo da perseguição é a perseguição. $\mathrm{O}$ objetivo da tortura é a tortura. $\mathrm{O}$ objetivo do poder é o poder." (ORWELL, 2009, p. 323)
} 
O termo mapa, para designar o conhecimento da verdade completa sobre o Grande Sistema, é aqui bem empregado, uma vez que os destinos programados a provocarem a rebelião dos Contaminados não conhecem escapatória se suas realidades são distorcidas pelas tecnologias de chips e computadores. O máximo que os habitantes da distopia podem conhecer é uma projeção da realidade, tal qual um mapa, a reconstruir o mundo. A partir de uma resolução completamente pessimista da (não-)adaptação de Ruam, como seria a empresa literária de Mauro Chaves uma alternativa epistemológica de envolvimento da realidade, mapa-múndi mais fiel que o saber dito técnico-científico?

Entendo que a crítica de base fantástica ao autoritarismo serve aqui como uma via de apreensão da experiência humana de características comparativas e projetivas. As primeiras dizem respeito a práticas da contemporaneidade, como a tortura institucionalizada da dissidência, o futebol, o carnaval, o tráfego de carros em São Paulo - com a intenção de ancorar a experiência dos leitores com relativa proximidade às suas próprias vivências. As segundas forçam uma imaginação futurista com objetivo claro de discutir os processos político-culturais que o Brasil dos anos 70 atravessa: o futebol como política do pão e circo, a industrialização das grandes cidades e os efeitos das mudanças climáticas, e, claro, as entranhas de regimes não democráticos. Também comparativo, portanto, este dispositivo literário projetivo tem a distinção, em Chaves, de sobrepor-se ao tema de sua diegese. Ao provocar a dúvida dos leitores sobre a verificabilidade do Grande Sistema pelos regimes de verdade que o próprio escritor estabeleceu, a sua projeção de um Brasil de 1975 ganha um combustível crítico que indaga a elite leitora da ficção-científica sobre o futuro do Brasil. Parece caber, portanto, à crítica da novela, algo entre a flexível manipulação pelo sistema, ou seu fim por conta da impossível adaptação. Como propôs Leomir Cardoso Hilário (2013), expor esses impasses que espelham a deterioração do mundo político também se constitui em uma desbarbarização dos laços sociais da atualidade (p. 213), e portanto, perfaz necessária atitude em seu tempo. $\mathrm{O}$ ato de duvidar dos modos de conhecimento institucionalizados e enviesados toma forma na literatura e acaba por revelar as ansiedades e chagas de um país assolado pela repressão política. Radical, Adaptação do funcionário Ruam se engrandece como projeto que não se furta em imaginar a violência com que os corpos disciplinados por regimes 
autoritários são utilizados - em 1975 ou antes disso, e no futuro. Por essa razão, na sua denúncia atravessada pela ótica do desejo dos sistemas opressores, a novela traz à luz representações da tortura e da contaminação que se convertem em documentos artísticos valiosos para que reflitamos sobre o passado e o presente de um Brasil autoritário.

\section{Referências Bibliográficas}

BOOKER, M. Keith. The dystopian impulse in modern literature: fiction as social criticism. Westport, Conn: Greenwood Press, 1994.

CHAVES, Mauro. Adaptação do funcionário Ruam. São Paulo: Perspectiva, 1975.

FOUCAULT, Michel. História da loucura na Idade Clássica. Tradução de Teixeira Coelho. São Paulo: Perspectiva, 1978.

FOUCAULT, Michel. Vigiar e punir: nascimento da prisão. Tradução de Raquel Ramalhete. Petrópolis: Vozes, 1999.

FREITAS FILHO, Armando; HOLLANDA, Heloísa Buarque de; GONÇALVES, Marcos Augusto. Anos 70: literatura. Rio de Janeiro: Europa, 1981.

GIL, Isabel Capeloa. Fragile Matters: Literature and the Scene of Torture. New German Critique, v. 43, n. 1 127, p. 119-140, fev. 2016.

HAMMOND, Andrew. The Palgrave handbook of Cold War literature. Brighton:

Palgrave Mcmillan, 2020.

HILÁRIO, Leomir Cardoso. Teoria crítica e literatura: a distopia como ferramenta de análise radical da modernidade. Anuário de Literatura, v. 18, n. 2, p. 201-215, 7 out. 2013.

ORWELL, George. 1984. Tradução de Alexandre Hubner e Heloisa Jahn. São Paulo: Companhia das Letras, 2009.

TAVARES, Gonçalo M. "Mil Novecentos e Oitenta e Quatro": totalitarismo, vigilância e linguagem. Um ensaio de Gonçalo M. Tavares. Expresso, Lisboa, 24 jan. 2021. Disponível em: https://expresso.pt/cultura/2021-01-24-Mil-Novecentos-e-Oitenta-eQuatro-totalitarismo-vigilancia-e-linguagem.-Um-ensaio-de-Goncalo-M.-Tavares. Acesso em: 30 jan. 2021.

VIEIRA, Fátima. The concept of utopia. In: CLAEYS, Gregory. (Org.). The Cambridge companion to utopian literature. Cambridge: Cambridge University Press, 2010. 